\title{
Effect of interlayer trapping and detrapping on the determination of interface state densities on high-k dielectric stacks
}

\author{
S. Dueñas, H. Castán, H. García, A. Gómez, L. Bailón, M. Toledano-Luque*, A. del Prado*, I. \\ Mártil*, and G. González-Díaz* \\ Departamento de Electricidad y Electrónica, E.T.S.I. Telecomunicación, Universidad de Valladolid, Campus "Miguel \\ Delibes", 47011 Valladolid, Spain. E-mail: sduenas(@ele.uva.es) \\ Departamento de Física Aplicada III (Electricidad y Electrónica), Facultad de Ciencias Físicas, Universidad Complutense, \\ 28040 Madrid, Spain
}

\begin{abstract}
Al} / \mathrm{HrO}_{2} / \mathrm{SiNx}: \mathrm{H} / \mathrm{n}-\mathrm{Si} \quad$ metal-insulatorsemiconductor (MIS) capacitors have been studied by electrical characterization. Films of silicon nitride were directly grown on n-type silicon substrates by electron-cyclotron-resonance assisted chemical-vapor-deposition (ECR-CVD). Silicon nitride thickness was varied from 2.96 to $6.64 \mathrm{~nm}$. Afterwards, $12 \mathrm{~nm}$ thick hafnium oxide films were deposited by the high-pressure reactive sputtering (HPS) approach. Interface state densities were determined by deep-level transient spectroscopy and simultaneous high and low frequency capacitance-voltage (HLCV). The simultaneous measurements of the high and low frequency capacitance voltage provide interface trap density values in the range of $10^{11} \mathrm{~cm}^{-2} \mathrm{eV}^{-1}$ for all the samples. However, a significant increase of this density of about two orders of magnitude was obtained by DLTS for the thinnest silicon nitride interfacial layers. In this work we probe that this increase is an artifact that must be attributed to traps existing at the $\mathrm{HFO}_{2} / \mathrm{SiN}_{\mathrm{x}}: \mathrm{H}$ interlayer interface. These traps are more easily charged or discharged as this interface comes near the substrate, that is, as thinner the $\operatorname{SiN}_{\mathrm{x}}: \mathrm{H}$ interface layer. The trapping/detrapping mechanisms increase the capacitance transient and, in consequence, the DLTS measurements have contributions not only from the insulator/substrate interface but also from the $\mathrm{HfO}_{2} / \mathrm{SiN}_{\mathrm{X}}: \mathrm{H}$ interlayer interface.
\end{abstract}

\section{INTRODUCTION}

High permittivity (high-k) dielectrics are nowadays being subject of great study in order to replace $\mathrm{SiO}_{2}$ as gate dielectric in metal-oxide-semiconductor field-effect transistors (MOSFET's) in the future scales of integration [1], [2]. To achieve performance comparable to silicon oxide, high- $k$ dielectrics have to fulfill some requirements: high quality interface with $\mathrm{Si}$, thermodynamic stability in contact with $\mathrm{Si}$, high recrystallization temperature, high bandgap and lower leakage conduction than silicon oxide at an equivalent oxide thickness. $\mathrm{HfO}_{2}$-based materials are among the most promising of such materials [1] - [3].

However, before these materials can replace $\mathrm{SiO}_{2}$ as gate dielectric, the nature and formation of electrically active defects existing in these emerging materials should be known. Defects in $\mathrm{SiO}_{2}$ are passivated by hydrogen, but this can cause some problems in $\mathrm{HfO}_{2}$ [4]. Moreover, as most of the high- $\mathrm{k}$ materials, when deposited in direct contact with $\mathrm{Si}$ an interfacial layer (few nanometers thick) is formed [5]. We have confirmed, in an earlier work, the formation of silicon oxide $\left(\mathrm{SiO}_{\mathrm{x}}\right)$ as interfacial layer when depositing $\mathrm{HfO}_{2}$ on $\mathrm{Si}$ [6]. This non-controlled interfacial layer can increase interfacial state density $D_{\mathrm{it}}$ and leakage current. The use of silicon nitride instead of silicon oxide as barrier layer can improve the effective capacitance of the gate dielectric stack, since silicon nitride has higher permittivity $(\approx 7)$ than silicon oxide $(\approx 3.9)$. Moreover, $\mathrm{SiN}_{\mathrm{x}}$ layer prevents the growth of silicon oxides when high-k dielectric is deposited and it's known that the use of nitrides greatly reduces boron diffusion from the heavily doped poly-Si gate electrode to the lightly doped Si channel [7].

In this work we focus our attention on the interface density as measured by two techniques: deep-level transient spectroscopy and simultaneous high and low frequency capacitance-voltage (HLCV). Hafnium oxide was grown by high pressure sputtering (HPS) using Ar as processing gas,

TABLE I

ECR-CVD DEPOSITION TIME, SILICON NITRIDE THICKNESS AND INTERFACE STATE DENSITIES PROVIDED BY DLTS AND HLCV MEASUREMENTS.

\begin{tabular}{lccccr}
\hline \hline Sample & $\begin{array}{c}\text { ECR } \\
\text { CVD } \\
\text { time (s) }\end{array}$ & $\begin{array}{c}\mathrm{SiN}_{\mathrm{x}}: \mathrm{H} \\
\text { thickness } \\
(\mathrm{nm})\end{array}$ & RTA & \multicolumn{2}{c}{$\mathrm{D}_{\mathrm{it}}\left(\mathrm{x} 10^{11} \mathrm{~cm}^{-2} \mathrm{eV}^{-1}\right)$} \\
\hline Asd_1 & 90 & $6,6 \pm 0,4$ & As-deposited & $3-5$ & 3.0 \\
RTA_1 & 90 & $6,6 \pm 0,4$ & $600^{\circ} \mathrm{C}, 30 \mathrm{~s}$ & $2-5$ & 2.2 \\
Asd_2 & 60 & $5,9 \pm 0,4$ & As-deposited & $0.8-1$ & 1.3 \\
RTA_2 & 60 & $5,9 \pm 0,4$ & $600^{\circ} \mathrm{C}-30 \mathrm{~s}$ & $1-2$ & 2.7 \\
Asd_3 & 30 & $3,9 \pm 0,2$ & As-deposited & Not & 4.5 \\
RTA_3 & 30 & $3,9 \pm 0,2$ & $600{ }^{\circ} \mathrm{C}-30 \mathrm{~s}$ & $\begin{array}{l}100-200 \\
\text { measured }\end{array}$ & 4.4 \\
Asd_4 & 15 & $3,0 \pm 0,4$ & As-deposited & $50-100$ & 2.0 \\
RTA_4 & 15 & $3,0 \pm 0,4$ & $600{ }^{\circ} \mathrm{C}-30 \mathrm{~s}$ & $50-100$ & 1.9
\end{tabular}




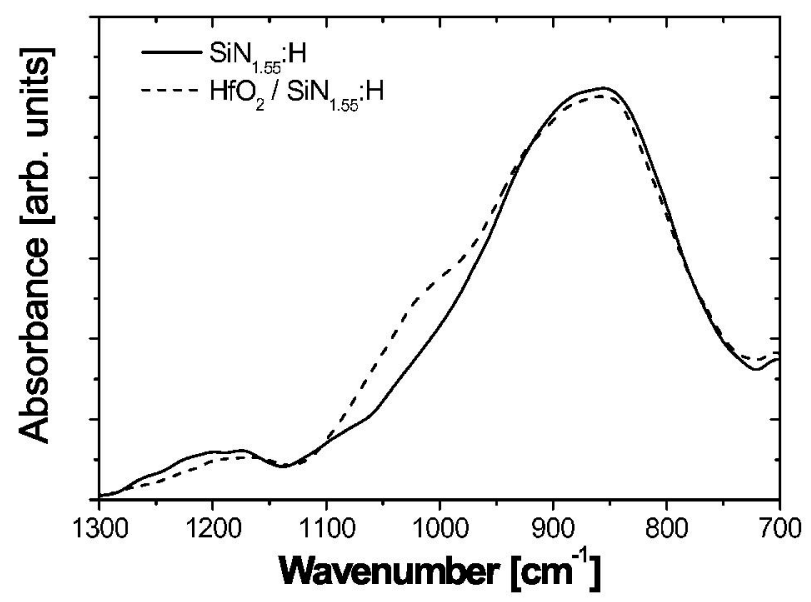

Fig. 1. FTIR spectrum of a $\mathrm{HfO}_{2} / \mathrm{SiN}_{\mathrm{x}}: \mathrm{H} / \mathrm{Si}$ stack (dotted line). Also shown, the FTIR spectra of a $\mathrm{SiN}_{\mathrm{x}}$ :H film (solid line). Notice that the peak position of the main $\mathrm{SiN}_{1 . x}: \mathrm{H}$ vibration is unaffected after the $\mathrm{HfO}_{2}$ plasma deposition process.

while silicon nitride was grown by electron cyclotron resonance - chemical vapor deposition (ECR-CVD), using $\mathrm{SiH}_{4}$ and $\mathrm{N}_{2}$ as precursors. We have studied the effect of $\mathrm{SiN}_{\mathrm{x}}: \mathrm{H}$ thickness in the electrical characteristics while keeping $\mathrm{HfO}_{2}$ thickness constant at $12 \mathrm{~nm}$.

\section{EXPERTMENTAL}

\section{A. Sample Preparation}

MIS structures were obtained as follows: substrates used were $\mathrm{n}$-Si (polished on one side, $5 \Omega \mathrm{cm}$ resistivity, $500 \mu \mathrm{m}$ thick). Before the dielectric films were deposited on the substrates, these were submitted to a standard RCA (Radio Corporation of America) cleaning. Deposition of silicon nitride was conducted in a home-made chamber attached to an ECR Astex 4500 Reactor. A mixture of high purity silane $\left(\mathrm{SiH}_{4}\right)$ and $\mathrm{N}_{2}$ were used as precursors. Deposition times were 90,60 , 30 and 15 seconds giving rise to four different thicknesses $(6.6,5.8,3.9$, and $3 \mathrm{~nm}$, respectively). Two series were obtained for each thickness, being one of them submitted to a rapid thermal annealing (RTA) at $600{ }^{\circ} \mathrm{C}$ for 30 seconds. Afterwards, $12 \mathrm{~nm} \mathrm{HfO}_{2}$ films were grown in an HPS system at pressure of 1.2 mbar during 30 minutes, keeping the temperature at $200^{\circ} \mathrm{C}$. High- $\mathrm{k}$ dielectric films were grown in a pure $\mathrm{Ar}$ atmosphere, because a preliminary study showed that these films presented an amorphous structure [8]. After the dielectric deposition, aluminum dot electrodes were e-beam evaporated through a shadow mask. Table I lists the samples obtained and the DLTS and HLCV experimental results.

The FTIR spectra of the $\mathrm{SiN}_{\mathrm{x}}: \mathrm{H}$ thin film, and the $\mathrm{HfO}_{2} / \mathrm{SiN}_{\mathrm{x}}: \mathrm{H}$ stacked structure obtained after $\mathrm{HfO}_{2}$ deposition in $\mathrm{Ar}$ atmosphere are shown in Fig. 1. The FTIR spectrum of the $\mathrm{SiN}_{\mathrm{x}}: \mathrm{H}$ layer has the characteristic Si-N stretching band located at $844 \mathrm{~cm}^{-1}$. After the $\mathrm{HfO}_{2}$ deposition, a smooth

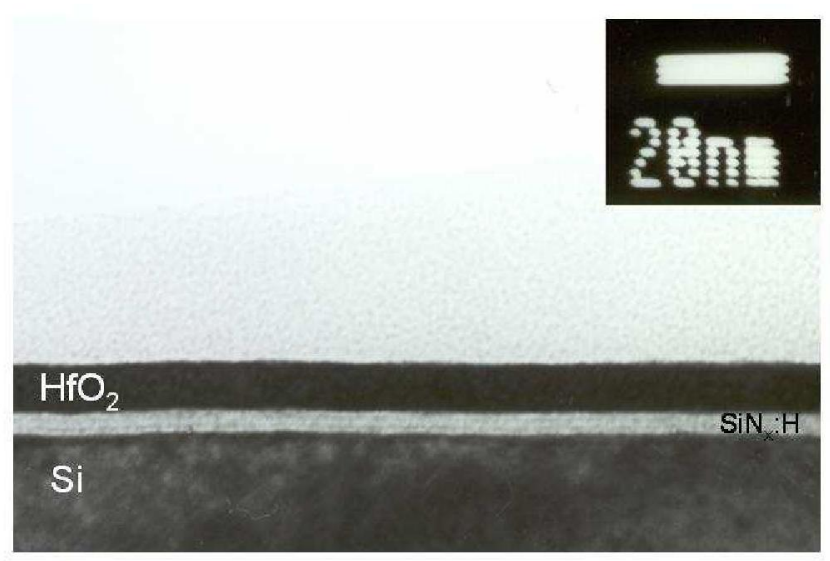

Fig. 2. Cross sectional image of a $\mathrm{HfO}_{2} / \mathrm{SiN}_{\mathrm{x}}: \mathrm{H}$ structure. $\mathrm{SiN}: \mathrm{H}$ thickness is $2.9 \mathrm{~nm}$.

shoulder-like feature appears at about $1018 \mathrm{~cm}^{-1}$, slightly above the frequency corresponding to the Si-O-Hf configuration $\left(970 \mathrm{~cm}^{-1}\right)$ [14]. We tentatively attribute this band to the vibration of bonding groups involving $\mathrm{Si}, \mathrm{O}, \mathrm{N}$, and $\mathrm{Hf}$ which may be formed at the $\mathrm{HfO}_{2} / \mathrm{SiN}$ interface in small concentration.

In Fig. 2, a TEM image of a typical structure in wich $\mathrm{SiN}_{x}: \mathrm{H}$ film has a $2.9 \mathrm{~nm}$ thickness is shown. From the figure, a smooth surface topography can be observed. Also well defined $\mathrm{SiN}_{\mathrm{x}}: \mathrm{H} / \mathrm{Si}$ and $\mathrm{HfO}_{2} / \mathrm{SiN}_{\mathrm{x}}: \mathrm{H}$ interfaces can be clearly seen. The TEM image shows that the $\mathrm{SiN}_{\mathrm{x}}: \mathrm{H}$ film is unaltered after the deposition of the amorphous $\mathrm{HfO}_{2}$ film in Ar plasma.

\section{B. Experimental results}

HLCV measurements summarized in Table I provide similar interface density $\left(D_{i t}\right)$ values $\left(2-4 \times 10^{11} \mathrm{~cm}^{-2} \mathrm{eV}^{-1}\right)$ for all the samples, regardless the silicon nitride layer thickness. In contrast, DLTS results (Fig. 3) are clearly arranged in two groups: one corresponding to the thickest samples which has $D_{\text {it }}$ densities from $8 \times 10^{10} \mathrm{~cm}^{-2} \mathrm{eV}^{-1}$ to $4 \times 10^{11} \mathrm{~cm}^{-2} \mathrm{eV}^{-1}$, in good agreement with HLCV results, and the other

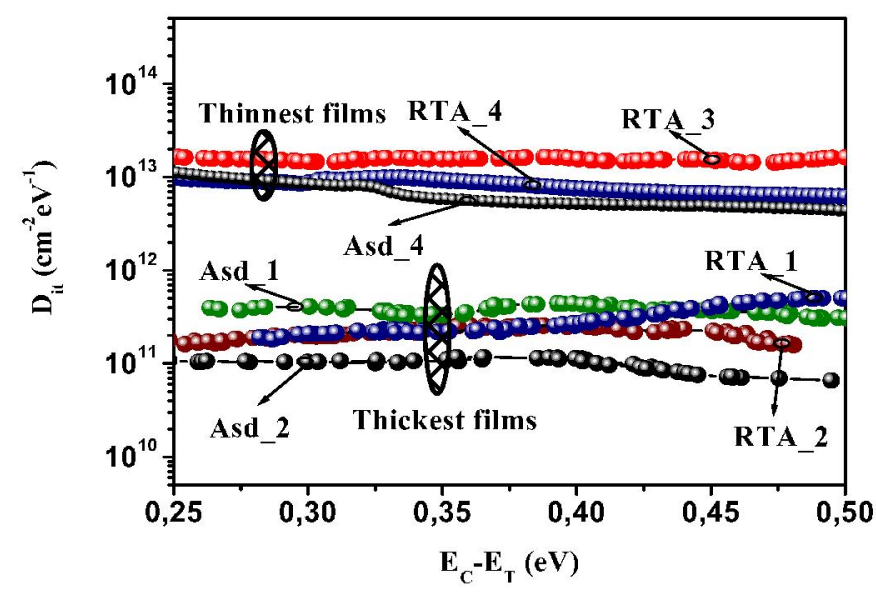

Fig. 3. Interfacial state densities measured by DLTS 


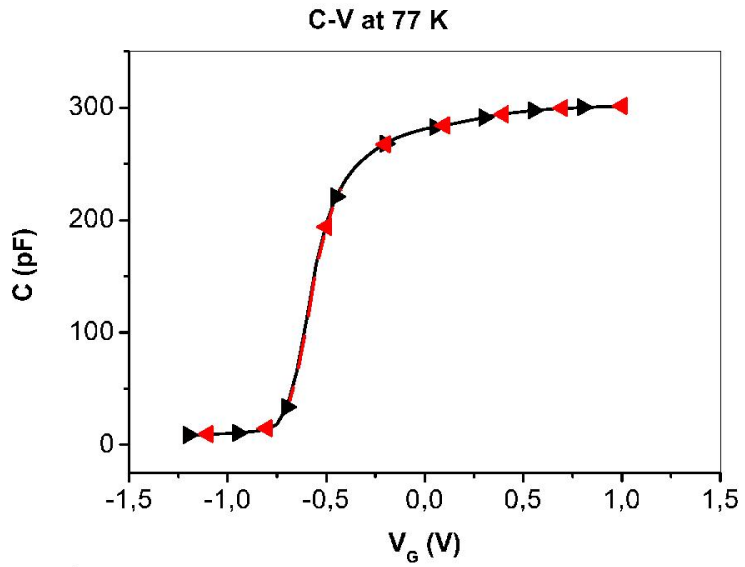

Fig. 4. $1 \mathrm{MHz} \mathrm{C}-\mathrm{V}$ curves for a $3 \mathrm{~nm} \mathrm{SiN}$ :H sample for voltage varying from reverse to accumulation $(\downarrow)$ and vice versa $(4)$.

corresponding to the thinnest samples with $D_{\text {it }}$ density values (from $6 \times 10^{12} \mathrm{~cm}^{-2} \mathrm{eV}^{-1}$ to $2 \times 10^{13} \mathrm{~cm}^{-2} \mathrm{eV}^{-1}$ ) much higher than those obtained by HLCV. In order to explain these discrepancies we have carried out an exhaustive analysis which lead us to conclude that charging and discharging mechanisms of inner traps existing at the $\mathrm{HfO}_{2} / \mathrm{SiN}_{\mathrm{x}}: \mathrm{H}$ affect the DLTS results. These mechanisms are tunneling assisted and, consequently, they become more important for the thinnest films.

Fig. 4 plots the $\mathrm{C}-\mathrm{V}$ curves for a sample with $3 \mathrm{~nm}$-thick $\mathrm{SiN}_{\mathrm{x}}: \mathrm{H}$ layer. The low stretch-out observed in $\mathrm{C}-\mathrm{V}$ means that the trap density is very low (contrary to the DLTS results). On the other hand, no hysteresis appears regardless the voltage swing direction, so indicating that slow traps which usually exist in the insulator bulk have also very low densities and do not affect the capacitance measurements. Therefore, we have to look for one other agent causing the above mentioned discrepancies between DLTS and HLCV and we focused our attention in the traps existing at the surface between the $\mathrm{SiN}_{\mathrm{x}}: \mathrm{H}$ interface layer and the $\mathrm{HfO}_{2}$ film.

(a)

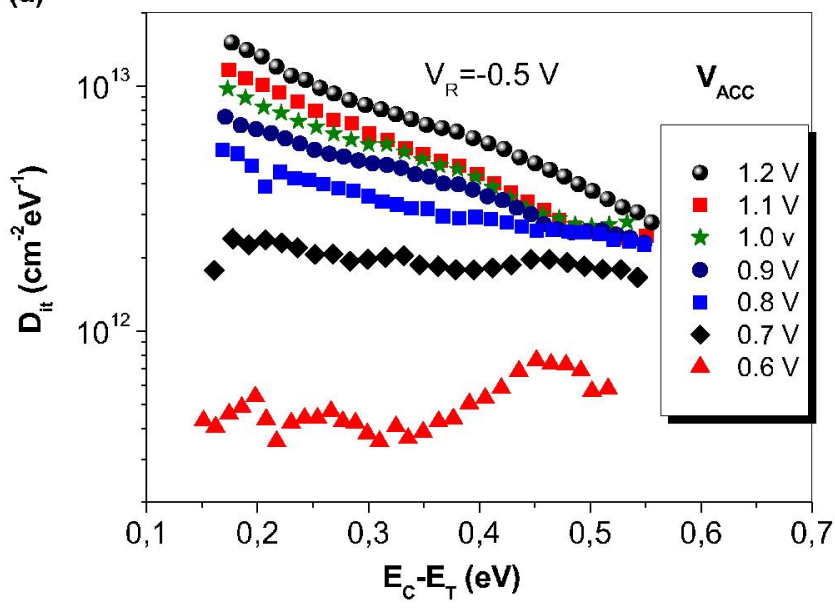

First, we have recorded the interface state density profiles obtained from DLTS when varying the bias conditions. Fig. 5(a) shows important variations in the $D_{\text {it }}$ profiles when the accumulation filling pulse voltage is varied while keeping constant the reverse voltage (when the capacitance transients are recorded). On the contrary, no significant differences are obtained when varying the reverse voltage (Fig. 5(b)). These results clearly indicate that is during the filling pulses when the mechanisms responsible for the extremely high DLTS profiles occur.

The energy band diagrams of the MIS structures under accumulation and inversion are displayed in Fig. 6. To construct them we have included the published values of the bandgap and the conduction and valence band offsets of hafnia and silicon nitride relative to silicon. We also assume that defects exist at the $\mathrm{HfO}_{2} / \mathrm{SiN}_{\mathrm{x}}: \mathrm{H}$ interface (inner layer interface defects, ILI defects) with energies in the whole $\mathrm{HfO}_{2}$ bandgap. DLTS measurements consist of applying accumulation pulses to fill the interface states in the upper half of the semiconductor bandgap followed by reverse pulses in which interface states emit electrons to the conduction band yielding the capacitance transients that are conveniently recorded and processed to obtain the $\mathrm{D}_{\text {it }}$ distribution. If the $\mathrm{SiN}_{\mathrm{x}}: \mathrm{H}$ film is thin enough, tunneling between the semiconductor and the inner layer interface (ILI) may occur. At accumulation, ILI states are filled by capturing electrons coming from the semiconductor conduction band by direct tunneling. Then, when the reverse pulse is applied these defects emit the captured electrons to the semiconductor band. These processes may occur in two different ways: For energies ranging from the Fermi level to the semiconductor conduction band, by tunneling between the ILI states and the interface states. Afterwards, these interface states emit electrons to the conduction band in a similar way as occurs in conventional DLTS. This extra charge increases the amplitude of the capacitance transients and, consequently, the DLTS interface

(b)

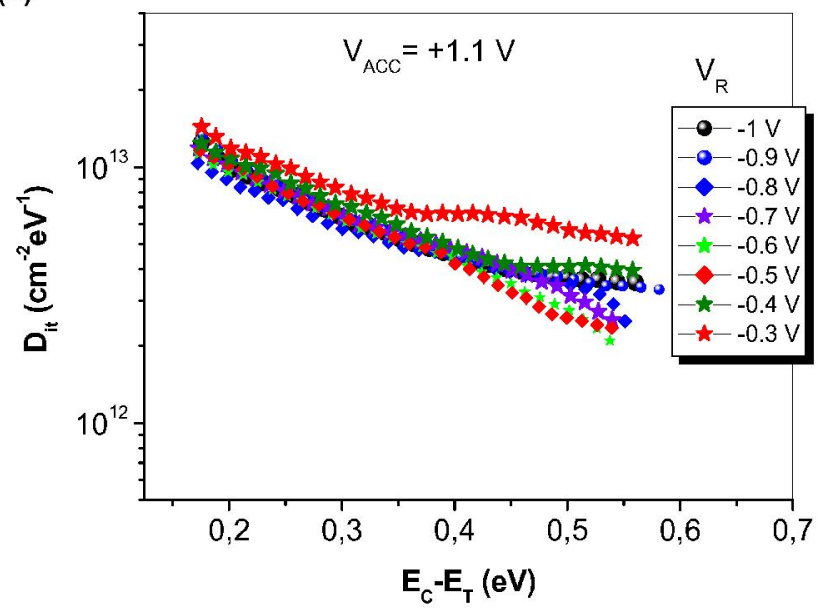

Fig. 5. DLTS profiles obtained keeping constant the voltage of the reverse-emptying-pulse (a) and the accumulation-filling pulse (b). 


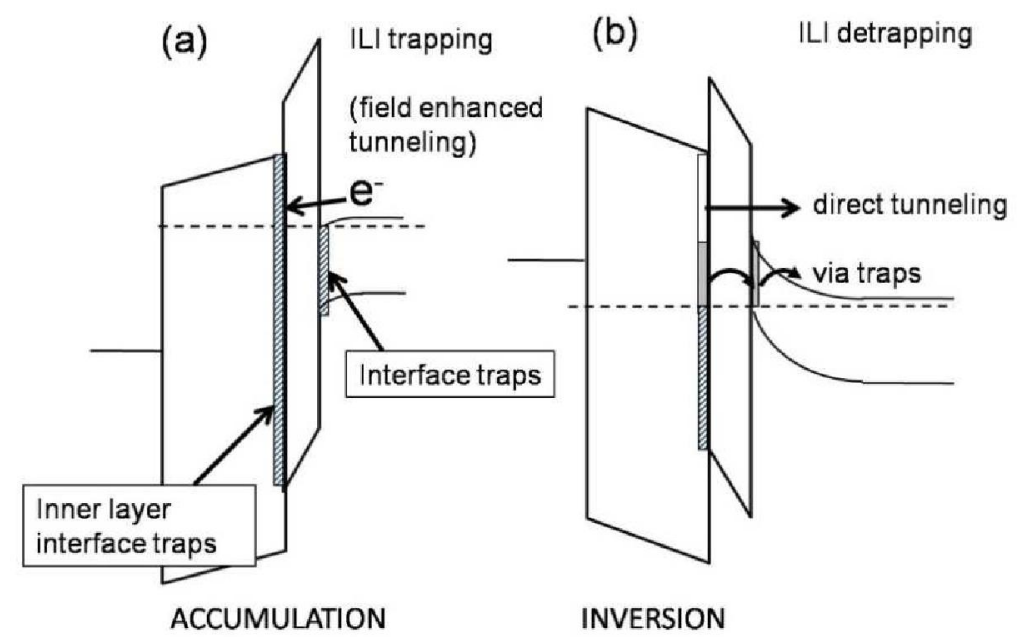

Fig. 6. Energy band diagram of the $\mathrm{HfO}_{2} / \mathrm{SiN}_{\mathrm{x}}: \mathrm{H} / \mathrm{Si}$ MIS structure at accumulation (a) and inversion (b).

state density values are derived. ILI states with energies over the silicon conduction band emit electrons by direct tunneling and, then, do not contribute to the DLTS results. Since all these mechanisms are tunneling assisted, as thinner the $\mathrm{Si}_{3} \mathrm{~N}_{4}$ film as higher their probability. In our experiment, the $\mathrm{Si}_{3} \mathrm{~N}_{4}$ layer thickness has been varied from around 3 to $6.6 \mathrm{~nm}$.

To estimate the relationship between the tunneling charging/discharging probabilities for two samples with different $\mathrm{Si}_{3} \mathrm{~N}_{4}$ thickness $\left(t_{I}\right.$ and $\left.t_{2}\right)$, we can use the following quantum mechanics expression:

$$
\frac{p_{1}}{p_{2}}=\exp \left[\frac{2 \pi \sqrt{2 m_{h} \varphi_{v}}}{h}\left(t_{1}-t_{2}\right)\right]
$$

where $m_{h}$ is the hole effective mass inside the barrier, $\overline{\varphi_{v}}$ is the mean barrier height, $t_{l}$ and $t_{2}$ are the barrier thickness and $h$ is the Plank's constant. For the h-well triangular barrier, $\overline{\varphi_{v}}=$ $\Delta E_{V} / 2$, where $\Delta E_{V}$ is the valence band offset of silicon nitride relative to silicon. Gritsenko et al. [9] reported values of $\Delta E_{V} \approx$ $1.5 \mathrm{eV}$ and $m_{h} / m_{0}=(0.3 \pm 0.1)$. Here $m_{0}$ is the free electron mass. These values yield a relation of $p_{1} / p_{2}=10^{-4}$ for two layers of 6 and $3 \mathrm{~nm}$, respectively, so indicating that the ILI trapping/detrapping mechanisms is negligible for thicker samples. However that is not the case for the thinnest ones, increasing the total charge emitted during the DLTS reverse pulses.

\section{CONCLUSION}

The significant increase on the interface density of about two orders obtained by DLTS for very thin silicon nitride layers in $\mathrm{HfO}_{2} / \mathrm{SiN}_{\mathrm{x}}: \mathrm{H}$ gate stacks is an artifact caused by tunneling assisted charging and discharging of traps existing at the $\mathrm{HfO}_{2} / \mathrm{SiN}_{\mathrm{x}}: \mathrm{H}$ interlayer interface. The trapping/detrapping mechanisms increase the capacitance transient and, in consequence, the DLTS measurements have contributions not only from the insulator/substrate interface but also from the $\mathrm{HfO}_{2} / \mathrm{SiN}_{\mathrm{x}}: \mathrm{H}$ interlayer interface. In summary, we can conclude that interface state densities obtained by DLTS in the specific case of the $\mathrm{HfO}_{2} / \mathrm{SiN}_{\mathrm{x}}: \mathrm{H} / \mathrm{Si}$ system provides overestimated $D_{i t}$ values for very thin silicon nitride layers.

\section{ACKNOWLEDGMENT}

The study was partially supported by the local government (Junta de Castilla y León) under Grant No. VA018A06, and by the Spanish TEC2007 under Grant No. 63318 and TEC2008 under Grant No. 06988-C02-O2.

\section{REFERENCES}

[1] J-P. Locquet, C. Marchiori, M. Sousa, J. Fompeyrine, and J. W. Seo, "High-k dielectrics for the gate stack," J. Appl. Phys., vol. 100, pp. 0516101(1-14), September 2006.

[2] J. Robertson, "High dielectric constant gate oxides for metal oxide Si transistors," Rep. Prog. Phys., vol. 69, pp. 327-396, February 2006.

[3] M. Houssa, L. Pantisano, L-Å Ragnarsson, R. Degraeve, T. Schram, G. Pourtois, S. De Gendt, G. Groeseneken, and M. M. Heyns, "Electrical properties of high- $\kappa$ gate dielectrics: Challenges, current issues, and possible solutions," Mat. Sci. and Eng. R, vol. 51, pp. 37-85, April 2006.

[4] M. Houssa, S. D. Gendt, J. L. Autran, G. Groeseneken, and M. M. Heyns, "Role of hydrogen on negative bias temperature instability in $\mathrm{HfO}_{2}$-based hole channel field-effect transistor," Appl. Phys. Lett., vol. 85, pp. 2101-2103, September 2004.

[5] M. H. Hakala, A. S. Foster, J. L. Gavartin, P. Havu, M. J. Puska, and R. M. Nieminen, "Interfacial oxide growth at silicon/high- $k$ oxide interfaces: First principles modeling of the $\mathrm{Si}-\mathrm{HfO}_{2}$ interface," J. Appl. Phys, vol. 100, pp. 043708(1-7), August 2006.

[6] S. Dueñas, H. Castán, H. García, A. Gómez, L. Bailón, M. ToledanoLuque, I. Mártil, and G. González-Díaz, "Electrical properties of highpressure reactive sputtered thin hafnium oxide high- $k$ gate dielectrics," Semicond. Sci. Technol., vol. 22, pp. 1344-1351, December 2007.

[7] G. D. Wilk, R. M. Wallace, and J. M. Anthony, "High-k gate dielectrics: Current status and materials properties considerations," J. Appl. Phys., vol. 89, pp. 5243-5275, May 2001.

[8] M. Toledano-Luque, E. San Andrés, J. Olea, A. Prado, I. Mártil, W. Bohne, J. Röhrich, and E. J. Strub, "Hafnium oxide thin fillms deposited by high pressure reactive sputtering in atmosphere formed with different $\mathrm{Ar} / \mathrm{O}_{2}$ ratios ", Mater. Sci. Semicond. Proc., vol 9, pp. 1020-1024, December 2006.

[9] V. A. Gritsenko and E.E. Meerson, "Thermally assisted hole tunneling at the $\mathrm{Au}_{-}-\mathrm{Si}_{3} \mathrm{~N}_{4}$ interface and the energy-band diagram of metal-nitrideoxide-semiconductor structures," Phys. Rev. B vol. 57(4), R2081-R2083, January 1998. 